\title{
Characterization of the Dissociation Behavior of Gas-Phase Protonated and Methylated Lactones
}

\author{
Tracy Donovan and Jennifer Brodbelt \\ Department of Chemistry and Biochemistry, University of Texas at Austin, Austin, Texas, USA
}

\begin{abstract}
The dissociation behavior of gas-phase protonated and methylated four-, five-, six-, and seven-membered ring lactones, some with methyl substituents in various positions, has been characterized by using a quadrupole ion trap mass spectrometer and a triple quadrupole mass spectrometer. The energy dependence of collisionally activated dissociation pathways was determined by energy-resolved mass spectrometry, and the dissociation behavior of the various protonated lactones was compared to that observed for protonated cyclic ketones and ethers of analogous ring size. The protonated cyclic ethers and ketones predominantly dissociated via dehydration, whereas the protonated lactones dissociated via losses of an alkene, ketene, and water. The dissociation behavior of the gas-phase methylated lactones formed from ion/molecule reactions with dimethyl ether ions was compared to the collisionally activated dissociation behavior of isomeric protonated methyl-substituted lactones. The methylation experiments indicated that the gas-phase addition of a methyl group may dramatically alter the favored dissociation pathways when compared to the simple protonated ions. (J Am Soc Mass Spectrom 1992, 3, 47-59)
\end{abstract}

$\mathrm{T}$ The characterization of lactones is significant for several reasons. First, they are biologically relevant molecules that have particular importance in the metabolism of carbohydrates, adenosine triphosphate, and reduced nicotinamide adenine dinucleotide phosphate [1]. Also, many natural products are lactones. These include sesquiterpene lactones, which have antitumor activities and cytotoxic properties [2], quabalactones, which have psychoactive effects [3], erythromycin, an antibiotic [4], and pyrrole lactones, which are potent plant growth regulators [5]. In addition, lactones are major components in kava resin, a plant extract possessing pharmacological properties as an anesthetic [6]. Some lactones are valuable as geomarkers used in fuel exploration [7]. These geolactones are thought to occur as intermediates in the abiogenic oxidation of certain carotenoids present in the fuel source. Additionally, polymerization of some lactones yields novel elastomers [8, 9] and nontoxic biodegradable polymers [10, 11]. Thus, there is great interest in correlating and predicting efficiency of lactone polymerization with ring size and substituent effects. Finally, from a fundamental standpoint, lactones are particularly interesting because

Address reprint requests to Jennifer Brodbelt, Department of Chemistry and Biochemistry, University of Texas at Austin, Austin, TX $78712-1167$ their bimolecular and dissociation reactions have not been extensively explored.

Mass spectrometric studies of lactones generally have been limited to characterization of the fragmentation behavior of lactones upon electron ionization (EI) [12-16]. For example, McFadden et al. [12] studied the effect of increasing aliphatic side chain length on the EI mass spectra of a series of lactones. These investigators observed significant abundances of fragment ions resulting from the cleavage of the side chain only when the side chain contained two or more carbon atoms. For side chains that were three or more carbons long, a rearrangement followed by elimination of a water molecule occurred, and loss of a second water molecule was seen when the side chain was more than four carbons long. Friedman and Long [13] studied fragmentation patterns of simple four and five membered ring lactones upon electron ionization. They observed multiple cleavages of the ring and methyl substituent loss. Mass spectrometric investigations of analytically relevant lactones were reported for kava lactones [17], quabalactones [18], pyrrole lactones [5], sesquiterpenoid lactones [19], lignan lactones [20], steroidal spirolactones [21], and secosteroids [22].

The EI mass spectra of the lactones mentioned above show some similar fragmentation pathways, and we predicted that simple protonated lactones of 
variable ring size would also dissociate via some common pathways. Therefore, in order to enhance the differentiation of small structural differences in related lactones, we chose to evaluate the dissociation behavior of lactone ions produced via methylation, an alternative electrophilic addition reaction. The addition of a methyl cation to the lactones would possibly affect specifically those reactions which involved sterically hindered transition states or formation of entropically unfavorable products. In fact, there have been many studies [23-25], both in solution and in the gas phase, which have examined the relationships between carbon and proton basicities, but in no cases have the effects of methyl cation addition versus proton addition on dissociation behavior of gas-phase ions been investigated.

In this work, the dissociation behavior of gas-phase protonated and methylated four-, five-, six-, and seven-membered ring lactones, some with methyl substituents in various positions, was studied in order to correlate ring size and substituent effects. The lactone structures are shown in Figure 1. Dissociation behavior was characterized by low energy collisionally activated dissociation (CAD) [26] in a triple quadrupole mass spectrometer and a quadrupole ion trap mass spectrometer, and the energy dependence of dissociation pathways was determined by energy-resolved mass spectrometry [27]. The dissociation behavior of the various protonated lactones was compared to that observed for protonated cyclic ketones and ethers of analogous ring size. The use of $\mathrm{CD}_{4}$ as a chemical ionization reagent, as well as high resolution and sequential collisional activation experiments, provided details about mechanisms and ion structures. Finally, the reactive chemistry of the ncutral lactones with dimethyl ether ions was examined using both a triple quadrupole and an ion trap mass spectrometer.

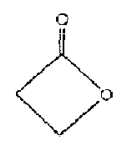

a

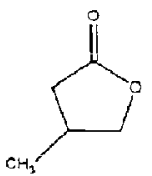

e

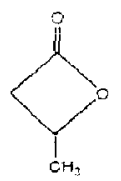

b

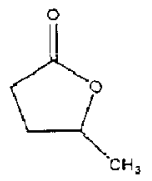

f

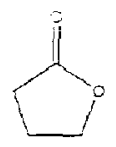

c

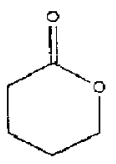

g

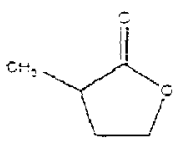

d

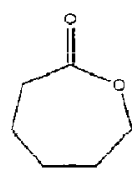

h
Figure 1. Lactone Structures: (a) $\beta$-propiolactone, (b) $\beta$ butyrolactone, (c) $\gamma$-butyrolactone, (d) $\alpha$-methyl- $\gamma$-butyrolactone, (e) $\beta$-methyl- $\gamma$-butyrolactone, (f) $\gamma$-valerolactone, (g) $\delta$ valerolactone, and (h) $\epsilon$-caprolactone.

\section{Experimental}

Energy-resolved mass spectra (ERMS) [27] were recorded for protonated lactones, cyclic ethers, and cyclic ketones by means of a Finnigan-MAT (San Jose, CA) Triple Stage Quadrupole (TSQ-70) mass spectrometer. Methane chemical ionization gas was admitted to nominally 3.4 torr as measured by a GranvillePhillips (Boulder, $\mathrm{CO}$ ) thermalconductivity gauge. Argon collision gas was introduced at $\mathbf{1 . 9}$ mtorr into the center collision quadrupole. This represents multiple collision conditions. Collision energy was raised in $5-\mathrm{eV}$ increments from 5 to $50 \mathrm{eV}$ for the energy-resolved breakdown curve experiments. CAD spectra were also recorded by a Finnigan-MAT Ion Trap Mass Spectrometer (ITMS) [28]. Helium buffer gas was admitted at 1 mtorr, and dimethyl ether chemical ionization gas was admitted at $1 \times 10^{-5}$ torr. The supplementary activation voltage typically was $0.3-0.5 \mathrm{~V}$ (p-p), applied for $5 \mathrm{~ms}$. Sample pressures were typically $8 \times 10^{-7}$ torr.

The lactones were also deuteronated with $\mathrm{CD}_{4}$ as a chemical ionization gas in both the TSQ and ITMS. ERMS and CAD spectra were recorded under the same conditions as used for the protonation experiments.

Reactions of the lactones with dimethyl ether ions were performed in the source of the TSQ or in the quadrupole ion trap, and the product ions were collisionally activated. In the TSQ, dimethyl ether was admitted to the source at a pressure of 1.4 torr, and argon collision gas was introduced to the second quadrupole at 1.7 mtorr. The collision energy was fixed at $20 \mathrm{~V}$. In the ITMS, dimethyl ether was introduced at nominally $1 \times 10^{-5}$ torr.

High resolution CAD spectra were recorded by using a home-built Fourier transform ion cyclotron resonance mass spectrometer (FTICR) [29] equipped with a 3-T magnet, a 5- $\mathrm{cm}^{3}$ cell, and an Extrel ANS (Madison, WI) FTMS 2000 data station. Dimethyl ether and analytes were admitted through a precision leak valve to a total pressure of $7 \times 10^{-8}$ torr. The ion/molecule reaction interval was $1 \mathrm{~s}$. Argon, the collision gas, was introduced through a pulsed valve. The gas pulse was followed by a $350-\mathrm{ms}$ delay. The estimated kinetic energy of ions during collisional activation was $200 \mathrm{eV}$. Broadband frequency excitâtion and detection was used for all experiments.

All lactones, ethers, and ketones were purchased from Aldrich Chemical (Milwaukee, WI). The $\mathrm{CD}_{4}$ was obtained from Cambridge Isotopes (Woburn, MA) and dimethyl ether was obtained from MG Industries (Valley Forge, PA).

\section{Results and Discussion}

The CAD behavior of simple protonated lactones was evaluated before the examination of the gas-phase 
methylated lactones was undertaken. Specific fragment ions of interest were characterized by sequential collisional activation experiments, by deuterium labeling studies or by high resolution FTMS experiments, and the details of the structural elucidations are presented in the following sections.

\section{CAD of Protonated Cyclic Ethers, Ketones, and Lactones}

ERMS reveals information about the favorabilities of various competitive dissociation pathways for a selected ion upon collisional activation [27]. ERMS can be used to distinguish structural differences of isomeric ions, and correlate fragmentation behavior for related compounds. The energy-resolved mass spectra of protonated cyclic ketones and ethers were examined in order to compare the dissociation trends of these related cyclic oxygen-containing molecules with the trends of lactones. The ERMS for all the protonated ethers and ketones are shown in Figures 2 and 3 , respectively. In some cases, the trends for fragment

a
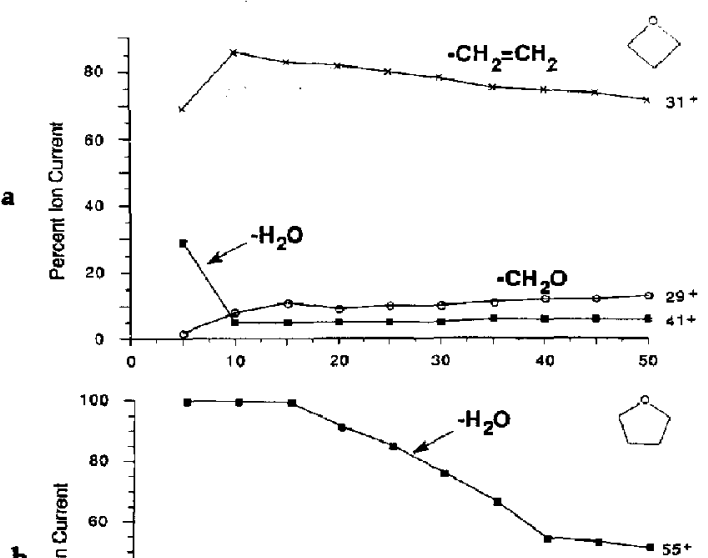

$\mathbf{b}$

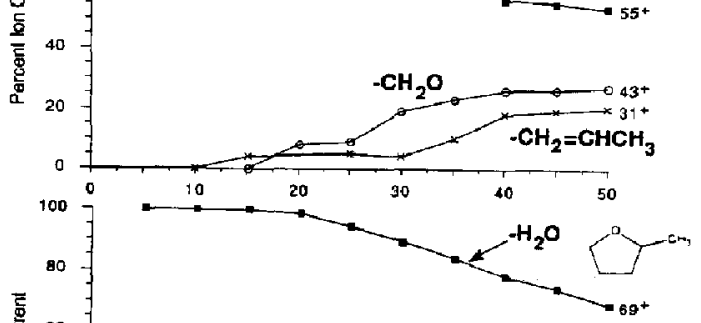

c

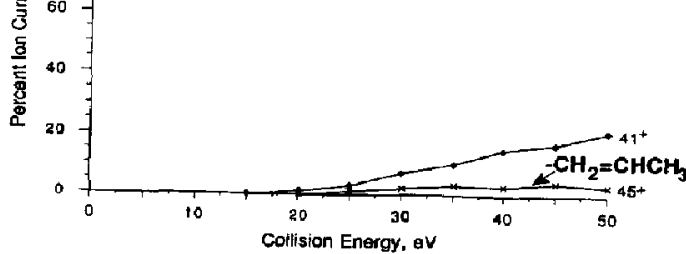

Figure 2. ERMS of protonated (a) trimethylene oxide $(m / z 59$ ) (b) tetrahydrofuran, ( $m / z$ 73), and (c) 2-methyltetrahydrofuran $(m / z 87)$. ions of low abundances have been omitted from the ERMS curves so that the trends of the ions of greater significance could be observed more easily.

Protonated cyclic ethers. Examination of the ERMS of protonated cyclic ethers reveals that at all collision energies, dehydration is the predominant dissociative channel for the protonated tetrahydrofuran and 2methyltetrahydrofuran, both five membered ring ethers. Possibly the dehydration process is not as important for protonated trimethylene oxide, the four membered ring ether, because the necessary oxygen attack on an adjacent proton is entropically disfavored for the four member transition state. Instead, a process involving ring opening and subsequent cleavage, yielding $\mathrm{CH}_{2} \mathrm{OH}^{+}$at $m / z 31$ due to loss of ethylene, is dominant. An analogous process may occur for 2-methyltetrahydrofuran, resulting in $\mathrm{CH}_{3} \mathrm{CHOH}^{+}$at $m / z 45$ via loss of propene [30], and for the unsubstituted tetrahydrofuran, resulting again in $\mathrm{CH}_{2} \mathrm{OH}^{+}$ via propene elimination [31]. Finally, the unsubstituted ethers also dissociate via loss of formaldehyde (30 u). This latter process is not observed for 2-methyltetrahydrofuran. However, protonated 2-methyltetrahydrofuran has an accessible yet minor dissociation route via loss of $\mathrm{C}_{2} \mathrm{H}_{6} \mathrm{O}$, forming allyl cation at $\mathrm{m} / \mathrm{z}$ 41.

Protonated cyclic ketones. For the ERMS plots for the protonated cyclic ketones shown in Figure 3, the predominant dissociation pathway observed at lower energies is dehydration. The ERMS plots for the unsubstituted four and five membered rings also show major contributions due to loss of $28 \mathrm{u}$, likely as ethylene after ring opening as suggested previously [32]. Neither of the substituted isomers shows this propensity to lose ethylene, but protonated 3-methylcyclopentanone does have a dramatic trend for formation of $m / z 43$, presumably due to loss of $\mathrm{C}_{4} \mathrm{H}_{8}$ through the analogous pathway that resulted in loss of ethylene from the unsubstituted protonated cyclopentanone. This dissociation pathway is also observed to a lesser extent for the 2-methylcyclopentanone. All of the ketone isomers show losses of 42 and $44 \mathrm{u}$ via losses of ketene $\left(\mathrm{CH}_{2}=\mathrm{C}=\mathrm{O}\right)$ and $\mathrm{C}_{2} \mathrm{H}_{4} \mathrm{O}$, respectively.

Protonated lactones. As expected, the protonated lactones show much more complex energy-resolved breakdown curves than do the protonated cyclic ketones or ethers (Figures 4 and 5). Losses that appear consistently include water, 28, 42, 44, and $46 \mathrm{u}$, and all the lactones form a product ion at $m / z 45$. The structures of the resulting ions were determined through a combination of tandem mass spectrometry (MS/MS) experiments, deuterium labeling studies, and comparison of ERMS curves, and will be described in the following sections. 

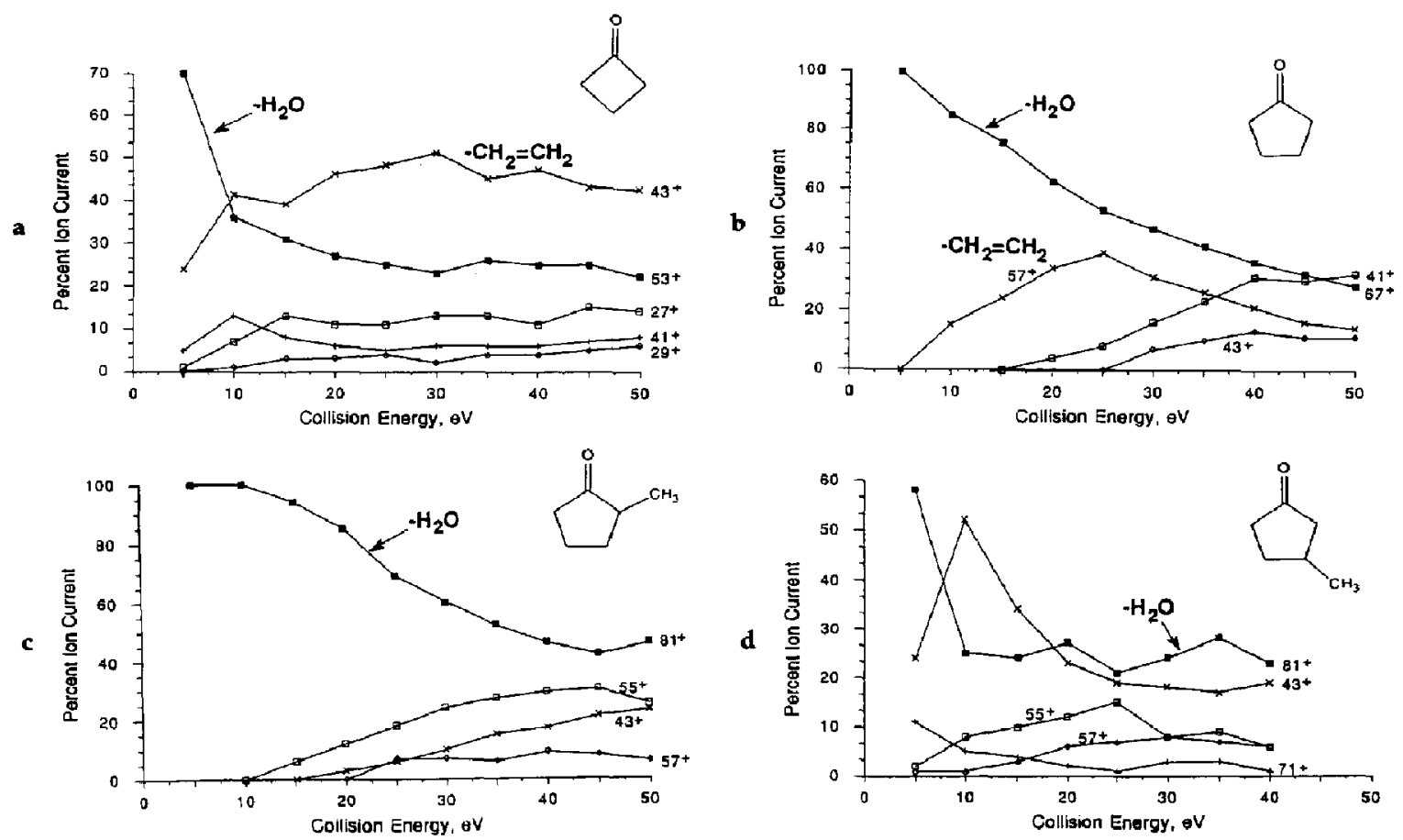

Figure 3. ERMS of protonated (a) cyclobutanone $(m / z 71)$, (b) cyclopentanone $(m / z$ 85), (c) 2-methylcyclopentanone ( $m / z 99)$, and (d) 3-methylcyclopentanone ( $m / z$ 99).

The process shown in many of the lactone ERMS plots that results in loss of $46 \mathrm{u}$ is attributed to sequential losses of $\mathrm{H}_{2} \mathrm{O}$ and $\mathrm{CO}$, and a mechanism is shown in Scheme I. The simplified mechanism shown does not account for the extensive hydrogen interchange that occurs via a separate process upon collisional activation of the selected ion (as discussed below). However, support for this mechanism was obtained through sequential collisional activation experiments in the quadrupole ion trap. The protonated ion was isolated and collisionally activated to promote dehydration, and then the dehydration product ion was isolated and activated. An example of this multistage experiment is shown in Figure 6. Protonated $\gamma$-valerolactone $(m / z 101)$ was activated to generate the CAD spectrum shown in Figure 6a. Isolation and activation of $m / z 83$, the dehydration product ion, results in $95 \%$ conversion to $m / z 55$. This dissociation route is very facile as evidenced by the mild activation conditions needed to promote this reaction, and the conversion efficiency is very high. Activation of $\mathrm{m} / \mathrm{z}$ 55 results in the spectrum shown in Figure 6c. Predominant losses are due to dehydrogenation, elimination of $\mathrm{CH}_{4}$, and elimination of $\mathrm{C}_{2} \mathrm{H}_{2}$; all of these are consistent with the dissociation pathways expected for a $\mathrm{C}_{4} \mathrm{H}_{7}^{+}$cation which is the end product ion shown in Scheme I.

To elucidate the structures of some of the other collisionally activated dissociation products of the protonated lactones, $\mathrm{CD}_{4}$ was used as an ionizing agent to promote the transfer of a deuteron rather than a proton to the lactones. Several effects must be considered when deuterium labeled compounds or deuterated chemical ionization reagents are used to elucidate mechanistic details [33-35]. First, there may be reversible atom exchange reactions that compete with dissociation of a selected energized ion. The extent of this atom scrambling depends on the ion's initial internal energy and its lifetime. In general, the complete randomization of hydrogen and deuterium atoms is disfavored at higher energies because direct cleavage and other dissociation processes with higher frequency factors become more favorable when the ion's internal energy exceeds the activation barriers for such pathways. Second, isotope effects alter the propensity for cleavages of bonds that involve hydrogen or deuterium owing to the differences in the zero point energies of the activated complexes. Typically, the activation energies for cleavage of bonds involving hydrogen are smaller than those involving deuterium. The isotope effect becomes more pronounced at lower internal energies where the small difference in the energies of the bonds involving hydrogen or deuterium has greater significance relative to the total energy available for distribution. These effects may occur during the initial formation of the ion (i.e., during ionization) or during subsequent activation of the ion (i.e., during collisional activation). For the examples discussed below, only stable $(\mathbf{M}+\mathrm{D})^{+}$ions are selected for subsequent collisional activation, and 
a
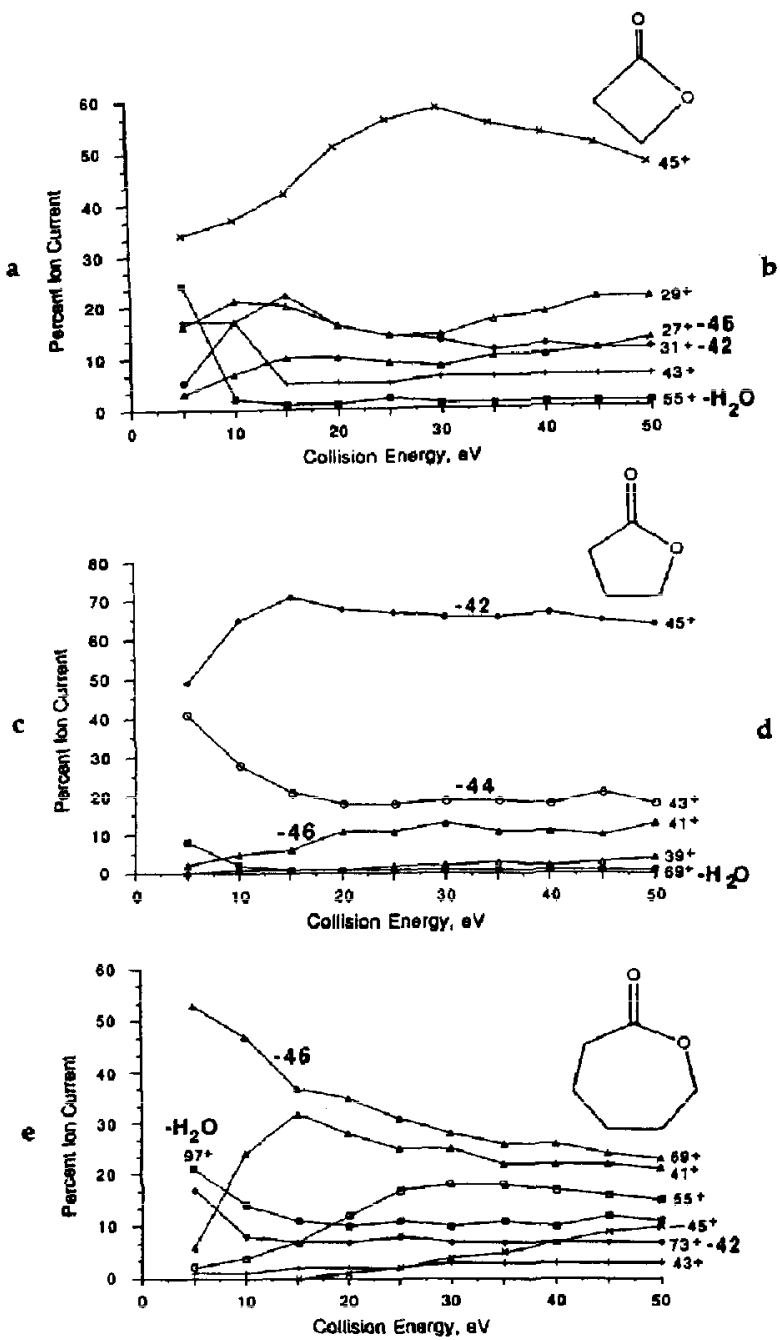

b

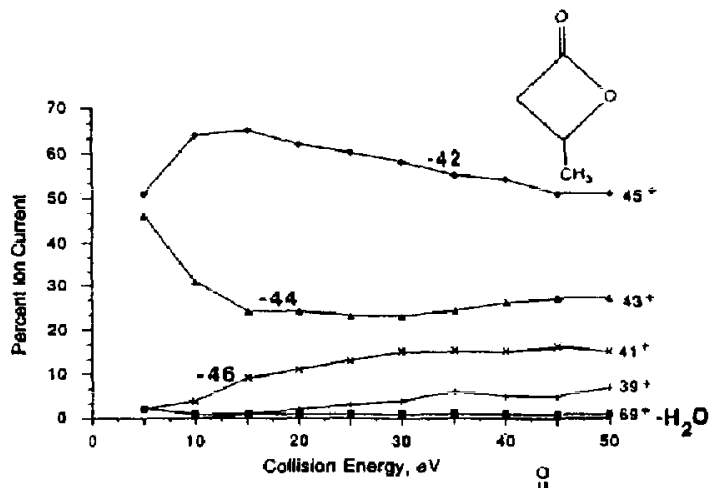

d

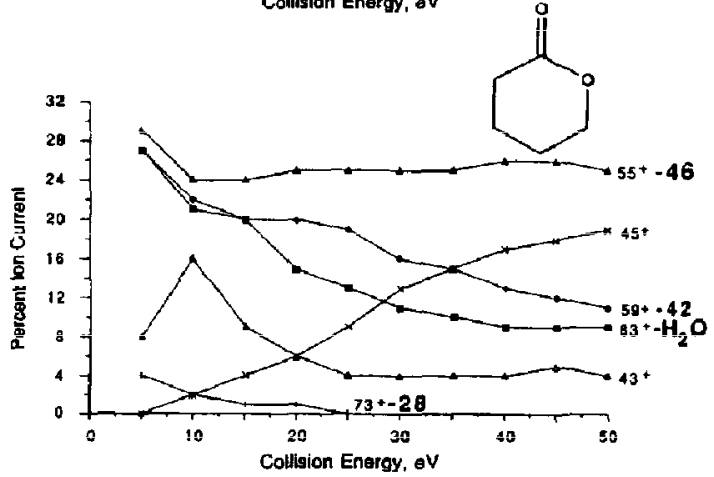

Figure 4. ERMS of protonated (a) $\beta$-propiolactone $(m / z$ 73), (b) $\beta$-butyrolactone $(m / z$ 87), (c) $\gamma$-butyrolactone $(m / z 87)$, (d) $\delta$-valerolactone $(m / z$ 101), and (e) $\epsilon$-caprolactone $(m / z 115)$.

it is assumed that the deuteron does not exchange with hydrogens of the lactones during the chemical ionization process. However, the conditions used to promote CAD (i.e., multiple activating steps) are energetic enough to result in extensive scrambling of the hydrogens and deuterium label and also to level isotope effects. This latter assertion is supported by the observation that the distribution of deuterium into the various fragment ions formed upon $\mathrm{CAD}$ is often statistical.

Deuteron transfer and CAD experiments were performed in the ITMS (application of $0.4 \mathrm{~V}$ (p-p) supplementary voltage). For each of the lactones, the $(\mathrm{M}+$ D) ${ }^{+}$ion was isolated, and then collisionally activated to induce dissociation. Upon collisional activation, the deuterium undergoes exchange with the hydrogen atoms and in most cases the randomization process is virtually complete prior to dissociation. Comparison of the experimental distribution of hydrogen and deuterium atoms in the resulting fragment ions to the calculated theoretical distributions of hydrogen and deuterium for all the possible elemental compositions for each ion provides insight into the fragment ion compositions. The ratios of the abundances of daughter ions with and without deuterium incorporation are listed in Table 1, along with the calculated distributions for the fragmentations. For example, the CAD spectra show that all the deuteronated lactones lose $\mathrm{H}_{2} \mathrm{O}$ and $\mathrm{HDO}$. In the CAD spectra of each of the deuteronated methyl-substituted five membered ring lactones ( $\alpha$-methyl- $\gamma$-butyrolactone, $\beta$-methyl- $\gamma$ butyrolactone, $\gamma$-valerolactone), the ratio of $\mathrm{H}_{2} \mathrm{O}$ loss to HDO loss is statistical, indicating extensive interchange of the $\bar{D}$ label. This is shown in Table 1 as the 

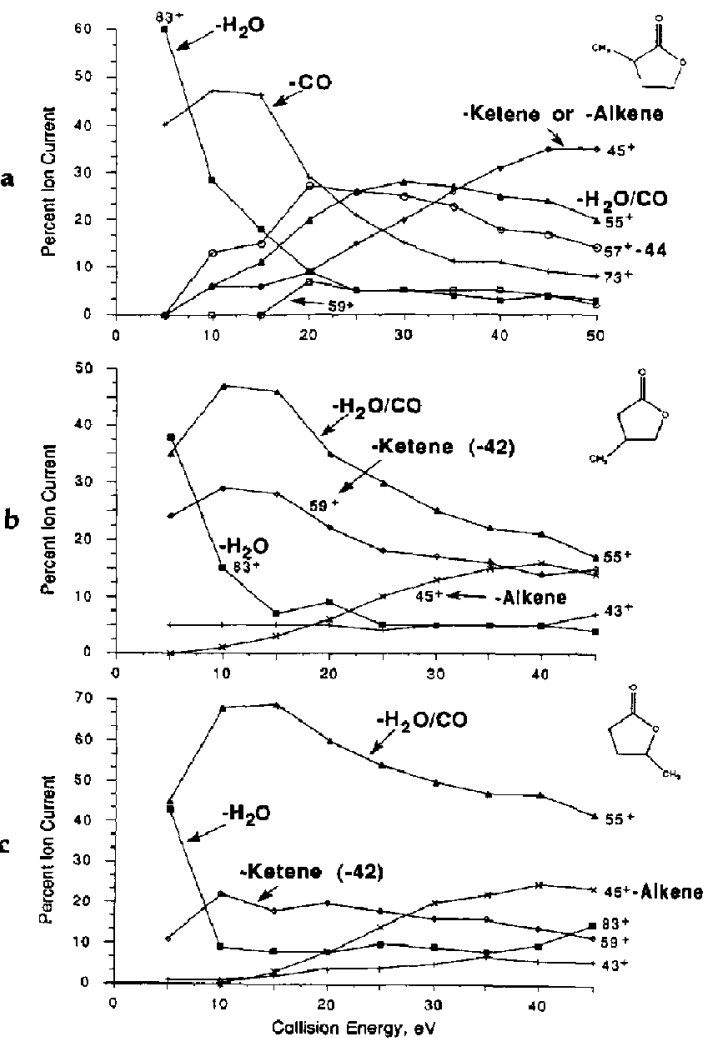

Figure 5. ERMS of protonated (a) $\alpha$-methyl- $\gamma$-butyrolactone ( $m / z$ 101), (b) $\beta$-methyl- $\gamma$-butyrolactone $(m / z 101)$, and (c) $\gamma$-valerolactone $(m / z 101)$.

ratio of $m / z 83 / 84$. The statistical ratio is $1: 3.5$, and the lactones all give ratios of $1: 3$ to $1: 4$. Relative ion abundances vary by $10-20 \%$ when reproducing data in the ITMS, so the agreements in the ratios shown in Table 1 are respectable.

Protonated and deuteronated $\gamma$-butyro and $\beta$ butyrolactones produced similar CAD spectra, so the compositions of their fragment ions are discussed together. Both protonated ions produce predominantly $m / z 45$ and some $m / z$ 43. The ion of $m / z 43$ results from loss of $44 \mathrm{u}$, as either $\mathrm{CO}_{2}$ or $\mathrm{C}_{2} \mathrm{H}_{4} \mathrm{O}$. If $\mathrm{m} / \mathrm{z} 43$ is $\mathrm{C}_{3} \mathrm{H}_{7}^{+}$due to loss of $\mathrm{CO}_{2}$ from the protonated parent ion, then that fragment would shift

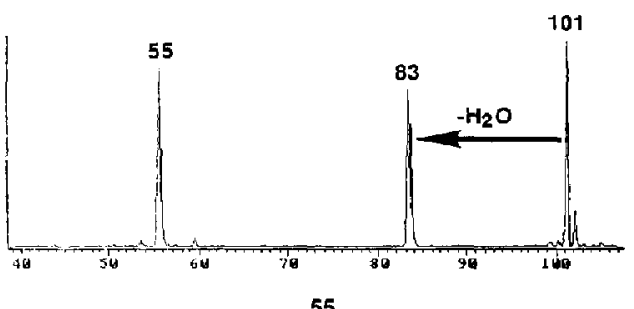

b

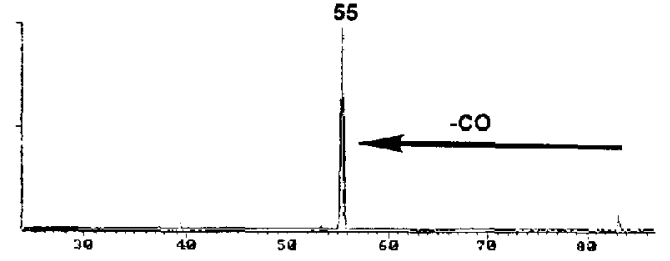

c

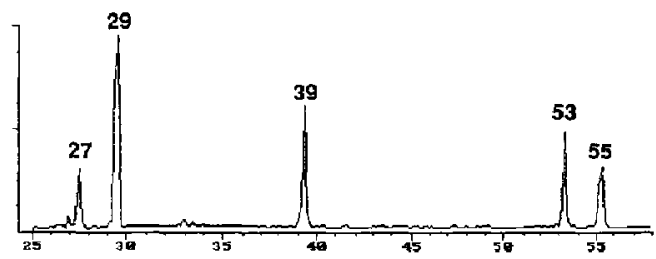

Figure 6. Sequential activation of $m / z 101$, then $m / z$ 83, then $m / z 55$ from protonated $\gamma$-valerolactone in the quadrupole ion trap.

quantitatively to $m / z \quad 44$ for dissociation of the deuteronated parent ion, since there is no elimination of $\mathrm{H}$ or $\mathrm{D}$ in the neutral fragment. However, $m / z 43$ remains the base peak for dissociation of the deuteronated butyrolactones, indicating that losses of both $\mathrm{C}_{2} \mathrm{H}_{4} \mathrm{O}$ or $\mathrm{C}_{2} \mathrm{H}_{3} \mathrm{DO}$ occur (formation of $\mathrm{C}_{2} \mathrm{H}_{3} \mathrm{O}^{+}$). Thus, loss of $\mathrm{CO}_{2}$ is not a major process. The dissociation mechanism that leads to formation of $m / z 45$ from protonated butyrolactone leads to a mixture of $\mathrm{m} / \mathrm{z} 45$ and 46 for the deuteronated lactone. The neutral loss of $42 \mathrm{u}$ could be either ketene $\left(\mathrm{CH}_{2}=\mathrm{C}=\mathrm{O}\right)$, leading to a calculated ratio of $\mathrm{m} / \mathrm{z}$ 45 to $\mathrm{m} / z 46$ of $2: 5$, or propene, leading to a ratio of $m / z 45$ to $m / z 46$ of $6: 1$. Loss of ketene with incomplete interchange of the deuteron and hydrogens best accounts for the observed ratio of 1:6 for $\mathrm{m} / \mathrm{z} 45$ to $m / z 46$ (see Table 1).

For deuteronated $\alpha$-methyl $\gamma$-butyrolactone, a fragment at $m / z 74$ must correspond to the $m / z 73$

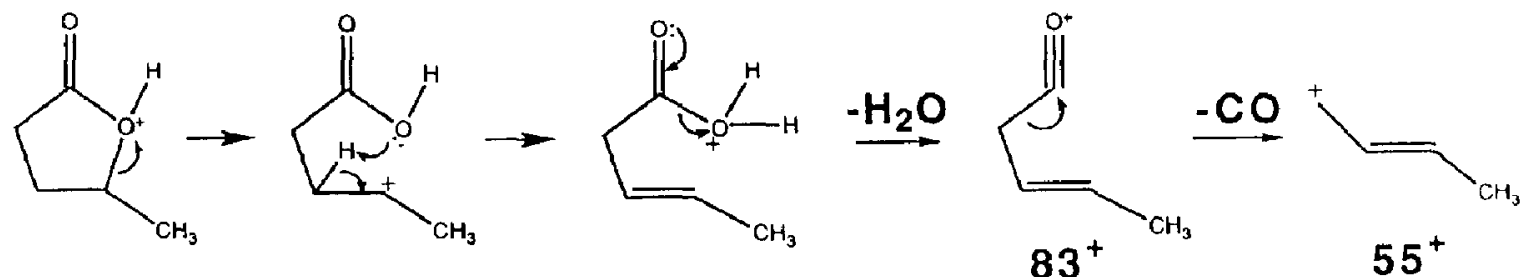

Scheme 1. Proposed mechanism for dehydration/decarbonylation route of protonated $\gamma$-valerolactone. 
Table 1. Ratios of CAD fragment ions with deuterium incorporation

\begin{tabular}{|c|c|c|c|c|c|}
\hline \multirow[b]{2}{*}{ Compound } & \multicolumn{5}{|c|}{ Daughter ion abundance ratios $(\mathrm{m} / \mathrm{z})$} \\
\hline & $43 / 44^{a}$ & $45 / 46^{\mathrm{D}}$ & $47 / 48^{\circ}$ & $69 / 70^{d}$ & \\
\hline & \multicolumn{5}{|c|}{ Experimental (theoretical) } \\
\hline$\gamma$-Butryolactone & $2: 1(1.3: 1)$ & $1: 6(2: 5)$ & - & $1: 2(1: 2.5)$ & \\
\hline$\beta$-Butyrolactone & $2: 1(1.3: 1)$ & $1: 6(2: 5)$ & - & $1: 2\{1: 2.5\}$ & \\
\hline \multirow[t]{3}{*}{$\beta$-Propiolactone } & $7: 10(1: 1.5)$ & $1: 50(0: 1)^{h}$ & $1: 2(2: 3)$ & - & \\
\hline & $55 / 56^{6}$ & $57 / 58^{i}$ & $59 / 60^{\circ}$ & $73 / 74^{n}$ & $83 / 84^{d}$ \\
\hline & \multicolumn{5}{|c|}{ Experimental (statistical) } \\
\hline$\gamma$-Valerolactone & $1: 4(1: 3.5)$ & - & $1: 100\{1: 3.5\}$ & - & $1: 3(1: 3.5)$ \\
\hline$\beta$-Methyl- $\gamma$-butyro & $1: 4\{1: 3.5\}$ & - & - & $1: 100(0: 1)$ & $1: 4(1: 3.5)$ \\
\hline$\alpha$-Methyl- $\gamma$-butyro & $1: 4\{1: 3.5\rangle$ & $3: 4(3: 3.6)$ & - & $1: 100(0: 1)$ & $1: 4(1: 3.5)$ \\
\hline
\end{tabular}

fragment from the protonated parent. In the deuteronated $\alpha$-methyl- $\gamma$-butyrolactone CAD spectrum, there is no fragment ion at $m / z$ 73. This restricts the loss to $\mathrm{CO}$, because loss of $\mathrm{C}_{2} \mathrm{H}_{4}$ in conjunction with the assumed scrambling process would produce both ions of $m / z 73$ and $m / z$ 74. Scrambling may occur in conjunction with the loss of $\mathrm{CO}$, but the resulting fragment ion retains all the hydrogens and deuterium label, and would therefore exclusively occur at $m / z 74$. The process that led to $m / z 57$ from protonated $\alpha$-methyl- $\gamma$-butyrolactone also accounts for the $\mathrm{m} / \mathrm{z} 58$ from the deuteronated parent. The ratio of $m / z 57$ to $m / z 58$ is statistical, assuming scrambling of the $\mathrm{D} / \mathrm{H}$ positions, and corresponds to the loss of $\mathrm{C}_{2} \mathrm{H}_{4} \mathrm{O}$. In addition, the ratio of ions generated by loss of 46 or $47 u$ is consistent with extensive scrambling prior to loss of $\mathrm{CO}$ and $\mathrm{H}_{2} \mathrm{O}$ (Table 1). In fact, all of the methyl-substituted five-membered ring lactones dissociate via loss of $\mathrm{CO}$ and $\mathrm{H}_{2} \mathrm{O}$ to form $\mathrm{m} / \mathrm{z}$ 55 and $m / z 56$ in the ratio of 1:4. The formation of $m / z 59$ and 60 from CAD of the deuteronated $\gamma$ valerolactone shows poor agreement with the statistical ratio (see Table 1). This anomalous behavior is under further investigation.

Deuteron transfer and collisional activation experiments performed with a triple quadrupole mass spectrometer yielded similar fragment ion distributions. Additionally, the TQMS was used to examine some of the isotopic distributions for those fragment ions which are not observed in the ITMS, such as the ion at $m / z 45$ for the methyl-substituted five-membered ring lactones. Examination of the ERMS trends for the lactones ionized by deuteron transfer from $\mathrm{CD}_{4}$ and calculation of the statistical isotopic distribution for the various fragment ion compositions indicates that in some cases two ion compositions are present as products of competitive mechanisms. For example, for deuteronated $\alpha$-methyl- $\gamma$-butyrolactone, the trends for formation of $m / z 45$ and $m / z 46$ support a twomechanism proposal (Figure 7). The abundance of $m / z 46$ increases sharply and reaches a plateau $>15$ $\mathrm{eV}$ collision energy, whereas the abundance of $\mathrm{m} / \mathrm{z}$ 45 remains constant. This suggests a change in the isotopic composition of these ions due to formation of two different structures. By comparison of these ratios to the theoretical statistical distributions, the ratio of $m / z 46$ to $m / z 45$ indicates that most of the ion current is due to loss of $\mathrm{C}_{3} \mathrm{H}_{4} \mathrm{O}$ (formation of $46^{+}$or $\mathrm{C}_{2} \mathrm{OH}_{4} \mathrm{D}^{+}$) and $\mathrm{C}_{3} \mathrm{H}_{3} \mathrm{DO}\left(45^{+}\right.$or $\left.\mathrm{C}_{2} \mathrm{OH}_{5}^{+}\right)$for collision energies $<15 \mathrm{eV}$. At higher collision energies, the ratio of $m / z 46$ to $m / z 45$ is much larger. This can be explained by assigning the $m / z 45$ ion composition as $\mathrm{CO}_{2} \mathrm{H}^{+}$and $m / z$ 46 as $\mathrm{CO}_{2} \mathrm{D}^{+}$. At higher collision energies, the scrambling process is not complete so most of the deuterium label remains on the original ionization site. The dissociation process which results in formation of $\mathrm{CO}_{2} \mathrm{D}^{+}$does not involve extensive

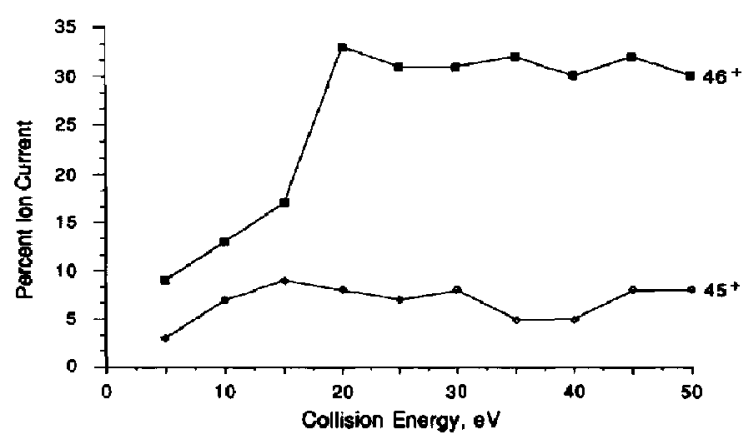

Figure 7. The energy-resolved trends for formation of $m / z 45$ and $m / z 46$ from deuteronated $\alpha$-methyl- $\gamma$-butyrolactone acquired with a triple quadrupole mass spectrometer. 
bond rearrangement, so it is more competitive than $\mathrm{H} / \mathrm{D}$ scrambling. Thus the abundance of $\mathrm{m} / \mathrm{z} 46$ is much higher than the abundance of $m / z 45$.

The assignment of these two ion compositions to the product ion at $m / z 45$ is further supported by a comparison of the ERMS recorded at a higher collision gas pressure (2.4 mtorr in the center quadrupole of the TQMS) to maximize the differences in the dissociation behavior of the protonated $\alpha$-methyl- $\gamma$ butyrolactone and $\gamma$-valerolactone (Figure 8 ). In the ERMS of the protonated $\gamma$-valerolactone, $m / z 59$ is observed at lower energies, whereas $m / z 45$ becomes more important at higher energies. In the ERMS of the protonated $\alpha$-methyl- $\gamma$-butyrolactone, the $m / z 45$ ion remains predominant at all collision energies, and $\mathrm{m} / \mathrm{z} 59$ is not formed. Dissociation of protonated $\gamma$-valerolactone by ketene elimination results in formation of $m / z 59$, whereas the analogous dissociation of protonated $\alpha$-methyl- $\gamma$-butyrolactone by methylketene elimination results in formation of $m / z 45$. These are the processes favored at lower collision energies. The relevant cleavages for formation of these ions are shown in Scheme IIA. For simplicity, hydrogen exchange is not accounted for in the scheme. The second dissociation process, favored at the higher collision energies, is also shown in Scheme IIB. In this case, the product ion formed from the isomeric lactones is $m / z 45, \mathrm{CO}_{2} \mathrm{H}^{+}$, regardless of the position of the methyl group. This process is favored at higher collision energies.
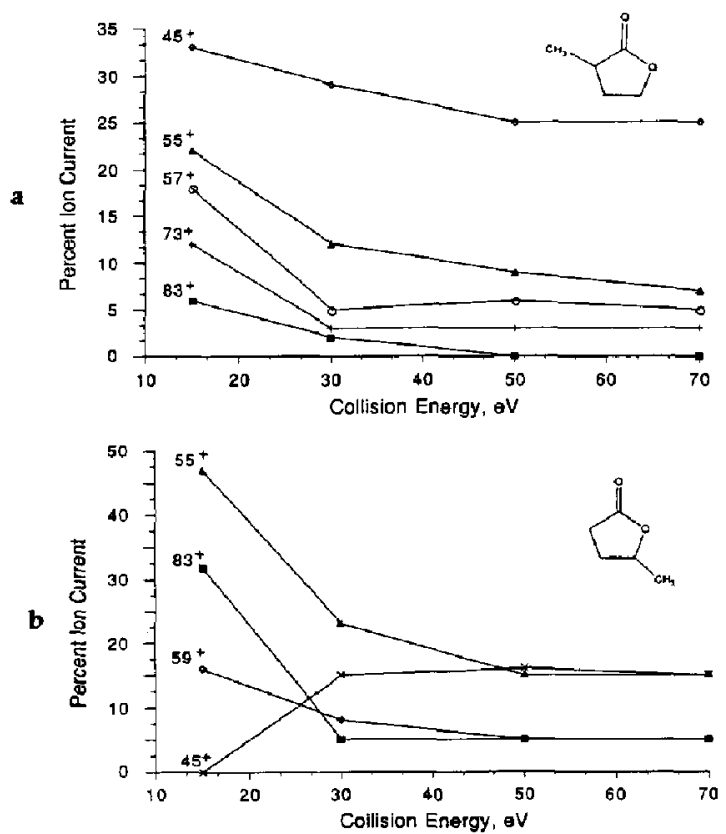

Figure 8. ERMS curves for protonated (a) $\alpha$-methyl- $\gamma$-butyrolactone and (b) $\gamma$-valerolactone $(m / z$ 101) acquired using a higher collision gas pressure (2.4 mtorr).

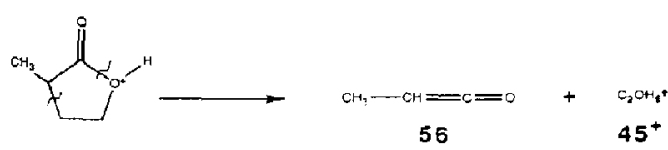

a

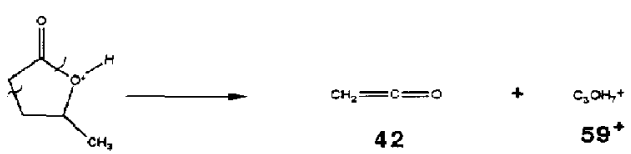

b<smiles>CC1CCC(O)C1=O</smiles>

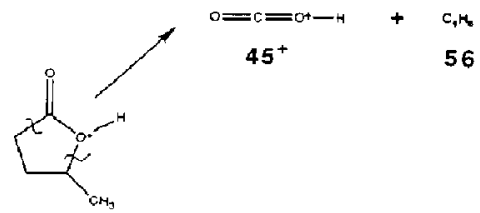

Scheme II. (A) Proposed dissociative process for formation of $m / z 45$ and $m / z 59$ from protonated $\alpha$-methyl- $\gamma$-butyrolactone and $\gamma$-valerolactone; (B) proposed secondary process for formation of $\mathrm{m} / z \mathbf{4 5}$ from protonated $\alpha$-methyl- $\gamma$-butyrolactone and $\gamma$-valerolactone.

In general, the lactones can be grouped into two categories based on one aspect of their dissociation behavior. The $\gamma$-valerolactone, $\beta$-methyl- $\gamma$-butyrolactone, and six and seven-membered rings do not dissociate via loss of $44 u, \mathrm{C}_{2} \mathrm{H}_{4} \mathrm{O}$, whereas the four and five-membered rings, and $\alpha$-methyl- $\gamma$-butyrolactone dissociate via loss of $\mathbf{4 4} \mathrm{u}$. This distinction will be an important feature in the later discussion of the reactive behavior of the lactones.

Comparison of related ring systems. The energy-resolved breakdown curves for the protonated fourmembered ring systems (trimethylene oxide, cyclobutanone, and propiolactone) provide some interesting comparisons. For these compounds, the trends for loss of water are virtually identical. The abundance of the dehydration process decreases abruptly at higher energies. Also, for all these four-membered ring species, losses of $44\left(\mathrm{C}_{2} \mathrm{H}_{4} \mathrm{O}\right)$ and 30 (formaldehyde) are observed.

In a comparison of the protonated unsubstituted frve-membered ring systems (tetrahydrofuran, cyclopentanone, and $\gamma$-butyrolactone), the first striking observation is that dehydration, which is so clearly favored for the ether and ketone, is only a minor contribution to the lactone spectrum. Also, both the ketone and ether have contributions owing to loss of formaldehyde, and this loss is absent from the lactone spectrum. The protonated ether fragments due to loss 
of $42 \mathrm{u}$, forming protonated formaldehyde. This also occurs for the lactone and to a smaller extent the ketone. The protonated ketone shows loss of $44 \mathrm{u}$, forming a propenyl ion which is not observed for protonated tetrahydrofuran, but this loss does occur for the protonated lactone, resulting in $\mathrm{C}_{2} \mathrm{H}_{3} \mathrm{O}^{+}$. The lactone produces a fragment due to combined dehydration and loss of $\mathrm{CO}$ (net $46 \mathrm{u}$ loss) which is not observed for either of the other systems.

\section{Comparison of ERMS in a Triple Quadrupole and a Quadrupole Ion Trap Mass Spectrometer}

Energy-resolved mass spectra of protonated $\alpha$-methyl- $\gamma$-butyrolactone acquired using a triple quadrupole mass spectrometer and a quadrupole ion trap mass spectrometer are shown in Figure 9. The trends for ions at $m / z 83,59$, and 57 are similar, whereas the ones for $m / z 55$ and 73 are somewhat different. In the TSQ, the fragment of $\mathrm{m} / z 73$ (loss of $28 \mathrm{u}$ ) is much more significant at all collision energies, while this process is only a minor contribution to the ion trap spectrum. The formation of $m / z 45$, the main fragment at higher energies in the TSQ, is not observed in the ion trap ERMS, and instead the abundance of $m / z 55$ (loss of $\mathrm{CO}$ and $\mathrm{H}_{2} \mathrm{O}$ ) increases in the ion trap. As discussed earlier, the sequential loss of $\mathrm{H}_{2} \mathrm{O}$ and $\mathrm{CO}$ is extremely facile and effcient in the quadrupole ion trap.

These differences can be explained when one considers the activation conditions used in each instru-
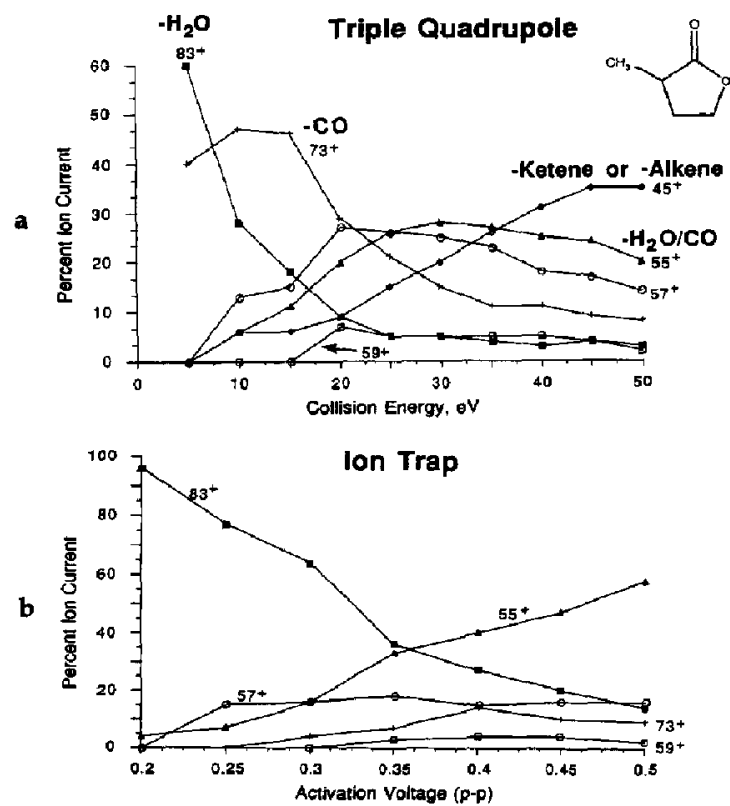

Figure 9. ERMS of protonated $\alpha$-methyl- $\gamma$-butyrolactone in (a) triple quadrupole and (b) quadrupole ion trap mass spectrometers. ment. The environment in the quadrupole ion trap is one which promotes many low energy collisions (potentially over 100 collisions in $5 \mathrm{~ms}$ ), whereas in the triple quadrupole instrument, fewer collisions of higher kinetic energy occur in a shorter time span. That is, a $30-\mathrm{eV}$ ion may pass through a quadrupole in $-20 \mu \mathrm{s}$ while undergoing three to eight collisions with argon. This results in fast, stepwise activation compared to the slow, stepwise activation in the quadrupole ion trap. Thus, certain reaction channels which have greater energy requirements are never accessible in the ion trap because activated ions can dissociate on a faster time scale than the collision frequency for subsequent supplementary activation. Likewise, those reactions which may require many collisions to promote extensive rearrangements may never be favorable in the triple quadrupole environment. The very low energy dehydration process is clearly favored in the ion trap mass spectrometer over a broad activation regime. In the triple quadrupole instrument, many more routes are competitive because pathways that have greater energy barriers may be accessed.

\section{Dissociation Behavior of the Gas-Phase Methylated Lactones}

Gas-phase methylation reactions of the various lactones induced by dimethyl ether ions were examined using the ion trap mass spectrometer and the triple quadrupole mass spectrometer with the objective of correlating the differences in product ion structures based on dissociation behavior. First the ion/molecule reactions were monitored as a function of time in the quadrupole ion trap to evaluate the distribution of product ions. As a representative case, the reaction product ion abundances are shown in Figure 10 for $\beta$-butyrolactone. As a function of time, the abundances of $(M+47)^{+}$and $(M+15)^{+}$increase while $(\mathrm{M}+\mathrm{H})^{+}$decreases. These are the only significant products observed, and they are similar for the other lactones. The $(M+47)^{+}$ions are likely proton-bound

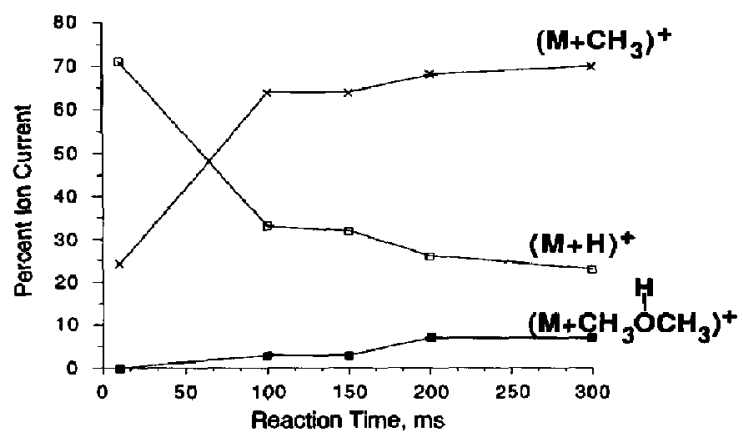

Figure 10. Dimethyl ether ion reactions with $\beta$-butyrolactone as a function of time in the quadrupole ion trap mass spectrometer. 
dimers, and dissociation of these ions yields information about their relative gas-basicities. This related investigation will be discussed in a future report.

More intriguing is a comparison of the collisionally activated dissociation behavior of the protonated and methylated ions. The CAD results are listed in Table 2, and representative spectra are shown in Figure 11 for two of the methyl-substituted five-membered ring lactones, $\alpha$-methyl- $\gamma$-butyrolactone and $\gamma$-valerolactone. There are two distinct categories into which the gas-phase methylated lactones can be grouped based on their dissociation behavior. For the six- and sevenmembered rings, and $\beta$ - and $\gamma$-methyl-substituted five-membered ring lactones, the dissociation behavior of the methylated species is directly analogous to that of the protonated species. Thus, for the gas-phase methylated $\gamma$-valero, $\beta$-methyl- $\gamma$-butyro, $\delta$-valero, and $\epsilon$-capro lactones (represented by Figure 11b), the predominant loss is via $60 \mathrm{u}$ (net loss of methanol and $\mathrm{CO}$ ), and the resulting daughter ion has the same mass-to-charge ratio as the predominant ion from dissociation of the protonated ion (net loss of $46 u$, water and $\mathrm{CO}$ ). Additionally, the ketene elimination route (loss of $42 u$ ) remains operative for the gas-phase methylated ions, and the dehydration pathway observed for the protonated ion instead becomes elimination of methanol for the methylated ion This behavior suggests that proton and methyl attachment sites are the same, and both protonated and methylated species dissociate by analogous pathways. The methylation reaction apparently does not dramatically alter the energetically or entropically accessible dissociation routes of this group of lactones.

However, for the remaining lactones, most of the smaller ring sizes including $\beta$-propio, $\beta$-butyro, $\gamma$ - butyro, and $\alpha$-methyl- $\gamma$-butyro lactones, the effect of gas-phase methylation on the dissociation behavior is dramatic. The major product ion from collisional activation of the $(M+15)^{+}$adducts is always $m / z 59$, and alternative dissociation routes are not competitive (except for $\beta$-propiolactone). This is not analogous to the behavior of the corresponding $(\mathrm{M}+\mathrm{H})^{+}$ions, as evident from the example shown in Figure 11a. The exception, $\beta$-propiolactone, also dissociates via several alternative pathways (albeit of modest importance) in addition to the predominant formation of $m / z 59$.

High resolution CAD spectra were recorded by using an FTICR to confirm the elemental compositions of the fragment ions of interest from the gasphase methylation reactions. The composition of $\mathrm{m} / \mathrm{z}$ 59 from gas-phase methylated $\gamma$-butyrolactone was found to be $\mathrm{C}_{3} \mathrm{H}_{7} \mathrm{O}^{+}$and not $\mathrm{C}_{2} \mathrm{H}_{3} \mathrm{O}_{2}^{+}$. This fragment ion is presumably due to elimination of ketene $\left(\mathrm{CH}_{2}=\mathrm{C}=\mathrm{O}\right)$. The ion of $\mathrm{m} / z 55$ from gas-phase methylated $\gamma$-valerolactone was determined to be $\mathrm{C}_{4} \mathrm{H}_{7}^{+}$, via net loss of $60 \mathrm{u}$, likely as losses of $\mathrm{CH}_{3} \mathrm{OH} / \mathrm{CO}$ (analogous to the $\mathrm{H}_{2} \mathrm{O} / \mathrm{CO}$ loss pathway for the protonated ion).

Sequential collisional activation experiments proved valuable for elucidation of the structure of the unusual ion of $m / z 59$ in the CAD spectra for the gas-phase methylated lactones of smaller ring size. An example is shown in Figure 12. The gas-phase methylated $\alpha$-methyl- $\gamma$-butyrolactone ion at $m / z 115$ was isolated and collisionally activated to produce $m / z 59$ (Figure 12a). In a second stage, this fragment ion was isolated and activated to produce the spectrum shown in Figure $12 \mathrm{~b}$. Isomeric $\mathrm{C}_{3} \mathrm{H}_{7} \mathrm{O}^{+}$ions with known structures [36] were generated from vari-

Table 2. CAD spectra of $(M+H)^{+}$and $(M+15)^{+}$ions of lactones ${ }^{a}$

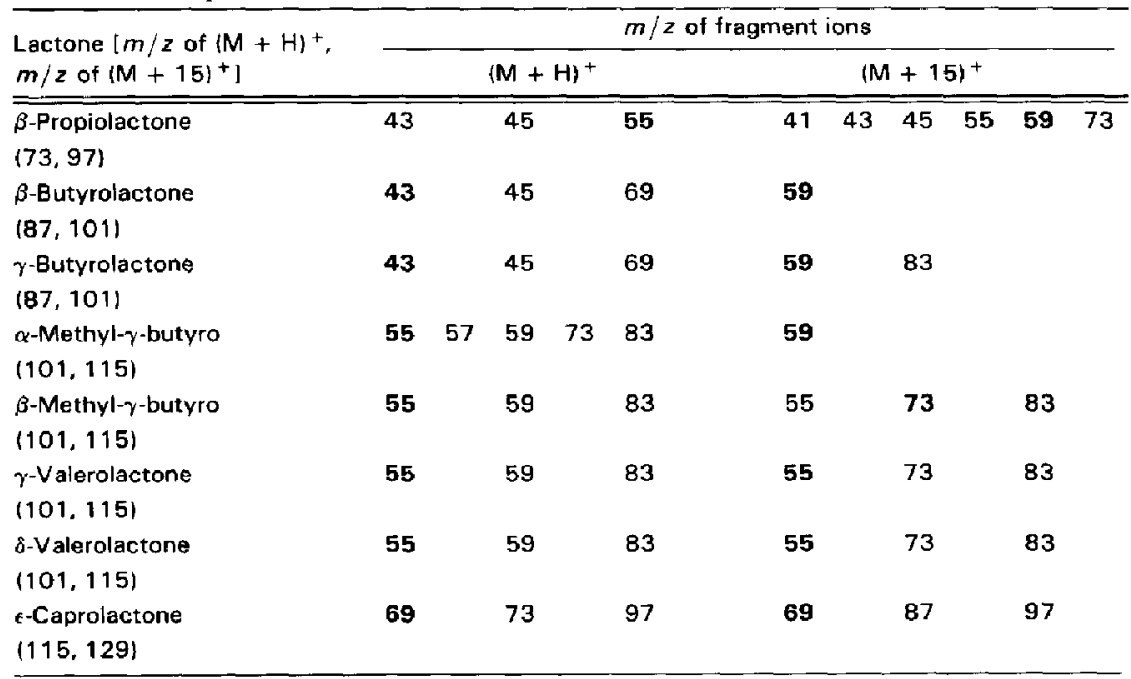

Acquired with an ITMS; most abundant ions are boldface. 


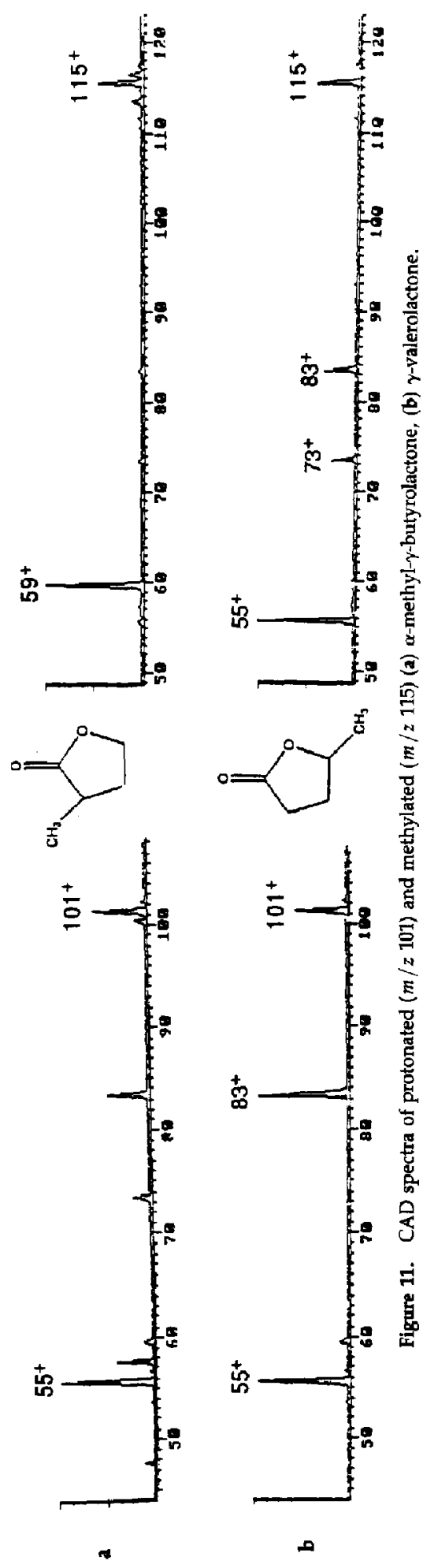



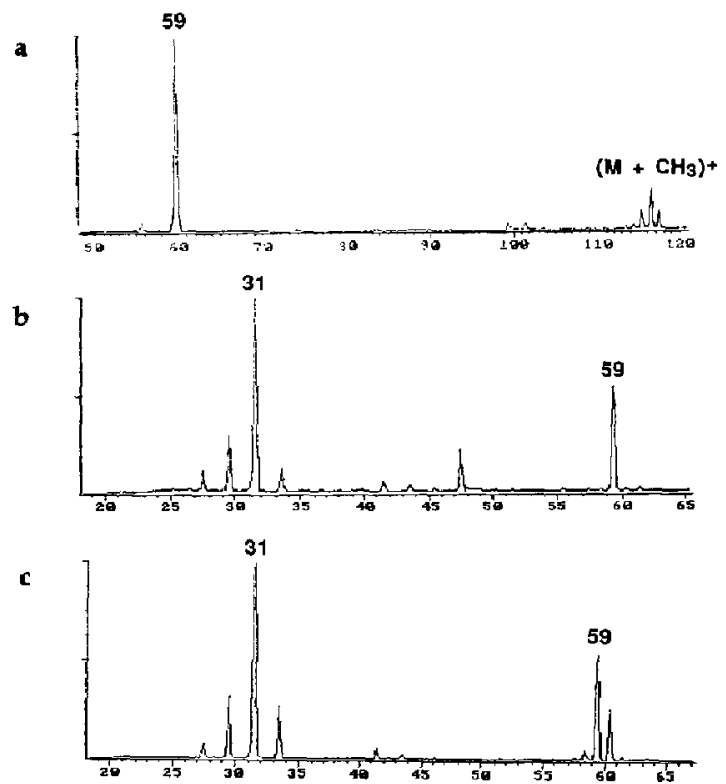

Figure 12. Sequential CAD spectrum for isolation and dissociation of $m / z 59$ from dissociation of $m / z 115$ of methylated $\alpha$-methyl- $\gamma$-butyrolactone and CAD spectrum of the $m / z 59$ from $\alpha$ cleavage of 3-methoxy-1-butanol acquired with a quadrupole ion trap.

ous precursors including vinyl methyl ether, 1,2-dimethoxyethane, and 3-methoxy-1-butanol, and their CAD spectra were recorded. The best match was obtained from the collisional activation of the ion of $\mathrm{m} / \mathrm{z} 59$ generated from electron ionization of 3methoxy-1-butanol ( $\alpha$ cleavage of $\mathrm{C}_{2} \mathrm{H}_{4} \mathrm{OH} \cdot$ ). The CAD spectrum for this model ion is shown in Figure 12c. This $\mathrm{C}_{3} \mathrm{H}_{7} \mathrm{O}^{+}$ion has the stable structure $\mathrm{CH}_{3} \mathrm{O}$ $=\mathrm{CHCH}_{3}$ [37]. A mechanism is proposed for formation of this ion at $m / z 59$ from the methylated $\alpha$ methyl- $\gamma$-butyrolactone (Scheme III). This mechanism shows methylation occurring at the ether oxygen site. Hydrogen interchange is not accounted for in the mechanism.

The groupings of the gas-phase methylated lac-

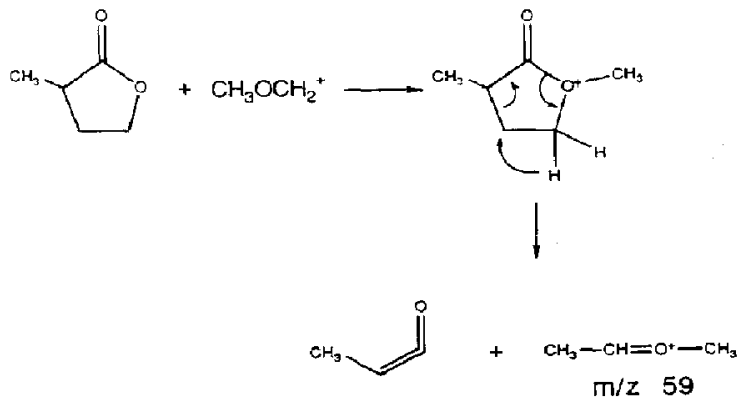

Scheme III. Mechanism of formation of $m / z 59$ from CAD of gas-phase methylated $\alpha$-methyl- $\gamma$-butyrolactone. tones based on dissociation behavior duplicate the groupings used to distinguish the protonated lactones based on dissociation behavior. The group consisting of the six- and seven-membered rings, $\beta$-methyl- $\gamma$ butyro- and $\gamma$-valero lactones did not dissociate via loss of $44 \mathrm{u}$ upon protonation and collisional activation, and this same group of lactones demonstrated analogous dissociation behavior upon gas-phase methylation. In contrast, the group containing the smaller lactone rings, including $\beta$-propio, $\beta$-butyro, $\gamma$-butyro, and $\alpha$-methyl- $\gamma$-butyro lactones, dissociated via loss of 44 u upon protonation and collisional activation, and this group of lactones produced predominantly only $m / z 59$ after gas-phase methylation and collisional activation. Thus, there is a striking dissociation distinction related to ring size and location of the methyl substituent among the series of lactones.

In the triple quadrupole mass spectrometer, reactions with dimethyl ether ions produce ions at $(\mathbf{M}+$ $\mathrm{H})^{+},(\mathrm{M}+15)^{+},(\mathrm{M}+45)^{+}$, and $(\mathrm{M}+47)^{+}$. The distinctive CAD behavior of the methylated lactones observed in the ITMS also is observed in the TQMS. That is, the same group of lactones always dissociates via formation of $\mathrm{m} / \mathrm{z} 59$ (retention of methyl group added), whereas the other group dissociates via pathways analogous to the protonated ion. The $(M+47)^{+}$ adducts fragment via two predominant channels, loss of neutral dimethyl ether or loss of neutral lactone. This suggests that these adducts are loose protonbound complexes. A quantitative study to evaluate the gas-basicities of these lactones by utilizing the kinetic method [38] is underway. In general, the $(\mathrm{M}+$ $45)^{+}$adducts dissociate via pathways that are analogous to those observed for the protonated and methylated lactones, suggesting that these are covalently bonded adducts.

There are two possible explanations for the striking differences in the bimolecular and dissociation behavior of the two groups of lactones. One group of the lactones has either smaller ring size or a methyl substituent occurs adjacent to the carbonyl position. These are sufficiently large structural differences that result in very different energetic and entropic barriers which affect the preferred site of methyl addition relative to the favored site of protonation. Perhaps protonation occurs at the carbonyl oxygen whereas methylation occurs at the ether oxygen for the group of smaller ring-size lactones. It has not been determined whether these ionization processes occur at the carbonyl oxygen, at the ether oxygen, or on the ring. However, the present results suggest that the group of lactones of larger ring size protonate and methylate at the same site, whereas the results do not support this for the lactones of smaller ring size. Second, the addition of a bulky, highly polarizable methyl cation to the lactones of smaller ring size may be more favorable to induce ring opening, resulting in acyclic products.

Of related interest is the comparison of the dissociation behavior of gas-phase methylated lactones to 
protonated methyl-substituted lactones. For example, protonated $\gamma$-valerolactone, $\beta$-methyl- $\gamma$-butyrolactone, and $\alpha$-methyl- $\gamma$-butyrolactone have the molecular composition $\mathrm{C}_{5} \mathrm{H}_{9} \mathrm{O}^{+}$, the same as gas-phase methylated $\gamma$-butyrolactone. As shown in Table 2, gas-phase methylated $\boldsymbol{\gamma}$-butyrolactone dissociates predominantly to $\mathrm{m} / \mathrm{z} 59$, elucidated as $\mathrm{CH}_{3} \mathrm{CH}=$ $\mathrm{JCH}_{3}$. However, this is not a major fragment ion for any of the protonated methyl-substituted five-membered ring lactones. This result is not surprising because the methyl-substituted lactones have methyl groups covalently bound to carbon atoms in the ring whereas the lactones methylated in the gas phase likely undergo methyl addition at one of the more nucleophilic oxygen sites.

\section{Conclusions}

The ERMS breakdown graphs are much more complex for protonated lactones than for protonated cyclic ketones or ethers. Protonated lactones characteristically fragment by dehydration, ketene loss, alkene loss, and loss of $\mathrm{CO}+\mathrm{H}_{2} \mathrm{O}$, whereas analogous cyclic ethers dissociate by dehydration, alkene loss, and formaldehyde loss, and cyclic ketones fragment by dehydration, alkene loss, ketene loss, and alcohol loss. A comparison of ERMS of protonated lactones in a triple quadrupole mass spectrometer and a quadrupole ion trap indicates that low energy dehydrations are favored in the ion trap, whereas many higher energy pathways are competitive in the triple quadrupole instrument. Deuterium labeling was used to elucidate the compositions of the resulting product ions.

The lactones undergo methyl cation addition upon ion/molecule reactions with dimethyl ether ions. CAD of these adduct ions reveals that the various lactones may be classified into two groups that have strikingly different dissociation behaviors. Both protonated and methylated adducts of the six- and seven-membered rings, $\gamma$-valerolactone, and $\beta$-methyl- $\gamma$-butyrolactone dissaciate via similar mechanisms. However, the methylated adduct ions of the $\beta$-propio, $\beta$-butyro-, $\gamma$-butyro-, and $\alpha$-methyl- $\gamma$-butyro-lactones dissociate predominantly to $\mathrm{C}_{3} \mathrm{H}_{7} \mathrm{O}^{+}$only, and this behavior is very different from that observed for the simple protonated ions which undergo the typical fragmentations mentioned above. Thus, the methyl cation addition process provides more information about distinguishing groups of related lactones than about distinguishing individual structurally similar lactones.

\section{Acknowledgments}

Professor Dave Laude and Dawn Riegner are gratefully acknowledged for acquiring the FTICR spectra. This work was supported by the Welch Foundation, the National Science Foundation (postdoctoral starter grant), and the Society of Analytical Chemists of Pittsburgh.

\section{References}

1. Rawn, J. D. Biochemistry; Harper \& Row: New York, 1983.

2. Ando, M.; Wada, T.; Kusaka,'H.; Takase, K.; Hirato, N.; Yanagi, Y. J. Org. Chem. 1987, 52, 4792.

3. Raffauf, R.; Zennie, T. Bot. Mus. Lett. 1981, $29,151$.

4. Koch, W. In Analytical Profiles of Drug Substances, Vol. 8; Florey, K., Ed.; Academic: New York, 1979; p 159.

5. Lynn, D. G.; Jaffe, K. J.; Cornwall, M.; Tramontano, W. I. Am. Chem. Soc. 1987, 109, 5858.

6. Keller, F.; Klohs, M. Lloydia 1963, 26, 1.

7. Carlisle, D. B. Biochem. J. 1964, 90, 1.

8. Kricheldorf, H. R.; Scharnagl, N. J. Macromol. Sci. Chem. 1989, A26, 951.

9. Sosnowski, S.; Stomkowski, S.; Penczek, S.; Reibel, L. Makromol. Chem. 1983, 184, 2159.

10. Jedlinski, Z.; Kowalczuk, M.; Kurcok, P.; Brzoskowska, L.; Franek, J. Makromol. Chem. 1987, 188, 1575.

11. Keul, H.; Hocker, H.; Leitz, E.; Ott, K.; Morbitzer, L. Makromol. Chem. 1988, 189, 2303.

12. McFadden, W. H.; Day, E. A.; Diamond, M. J. Anal. Chem. $1965,37,89$.

13. Friedman, L.; Long, F. A. J. Am. Chem. Soc. 1953, 75, 2832.

14. Millard, B. J. Org. Mass Spectrom. 1968, 1, 279.

15. Chen, P. H.; Kuhn, W. F.; Will, F.; Tkeda, R. M. Org. Mass Spectrom. 1970, 3, 149.

16. Honkanen, E.; Moisio, T.; Karvonen, P. Acta Chem. Scand. 1965, 19, 370.

17. Duffield, R. A. M.; Lidgard, R. O. Biomed. Environ. Mass Spectrom. 1986, 13, 621.

18. Pachuta, R. R.; Kenttamaa, H. I.; Cooks, R. G.; Zennie, T. M.; Ping, C.; Chang, C.; Cassady, J. M. Org. Mass Spectrom. 1988, 23, 10.

19. Boocock, D. G. B.; Waight, E. S. Chem. Commun. 1966, 4, 90

20. Duffield, A. M. J. Heterocycic Chem. 1967, 4, 16.

21. Boreham, D. R.; Ford, G. C.; Haskins, N. J.; Vose, C. W.; Palmer, R. F. Biomed. Mass Spectrom. 1978, 5, 524.

22. Dias, J. R.; Ramachandra, R.; Nassin, B. Org. Mass Spectrom. 1978, 13, 307.

23. Brauman, J. I.; Han, C.-C. I. Am. Chem. Soc. 1988, 110, 5611.

24. Hine, J.; Weimer, R. D. Jr. J. Am. Chem. Soc. 1965, 87, 3387.

25. Brauman, J. I.; Dodd, J. A.; Han, C.-C. In Nucleophilicity, Adv. Chem. Ser. 215; Harris, J. M.; McManus, S. P., Eds.; American Chemical Society: Washington, DC, 1987, p 23.

26. Levsen, K.; Schwarz, H. Mass Spectrom. Rev. 1983, 2, 77.

27. McLuckey, S. A.; Cooks, R, G. In Tandem Mass Spectrometry; McLafferty, F. W., Ed; Wiley: New York, 1983.

28. Louris, J. N.; Cooks, R. G.; Syka, J. E. P.; Kelley, P. E.; Stafford, G. C.; Todd, J. F. J. Anal. Chem. 1987, 59, 1677.

29. Laude, D, A. Jr,; Beu, S. C. Antl. Chem. 1989, 61, 2422.

30. Headley, J. V.; Harrison, A. G. Can. J. Chem. 1985, 63, 609.

31. Bowen, R. D.; Harrison, A. G. J. Chem. Soc., Perkin Trans. 2. 1981, 1544.

32. Sigsby, M. L.; Day, R. J.; Cooks, R. G. Org. Mass Spectrom. $1979,14,273$.

33. Yeo, A. N. H.; Williams, D. H. I. Am. Chem. Soc. 1969, 91, 3582.

34. Howe, I.; McLafferty, F. W. J. Am. Chem. Soc. 1971, 93, 99.

35. Neeter, R.; Nibbering, N. M. M. Org. Mass Spectrom. 1971, 5,735 .

36. Brodbelt-Lustig, J. S.; Cooks, R. G. Int. I. Mass Spectrom. Ion Processes 1988 86, 253.

37. McLafferty, F. W.; Sakai, I. Org. Mass Spectrom. 1973, 7, 971.

38. McLuckey, S. A.; Cameron, D.; Cooks, R. G. J. Am. Chem. Soc. 1982 103, 1313. 